This document is confidential and is proprietary to the American Chemical Society and its authors. Do not copy or disclose without written permission. If you have received this item in error, notify the sender and delete all copies.

\title{
Fluxapyroxad Haptens and Antibodies for Highly Sensitive Immunoanalysis of Food Samples
}

\begin{tabular}{|r|l|}
\hline Journal: & Journal of Agricultural and Food Chemistry \\
\hline Manuscript ID & jf-2017-03199q.R4 \\
\hline Manuscript Type: & Article \\
\hline Date Submitted by the Author: & $\mathrm{n} / \mathrm{a}$ \\
\hline Complete List of Authors: & $\begin{array}{l}\text { Mercader, Josep; IATA-CSIC, Preservation \& Food Safety Technologies } \\
\text { Abad-Somovilla, Antonio; Valencia University, Organic Chemistry } \\
\text { Abad-Fuentes, Antonio; IATA-CSIC, Preservation \& Food Safety } \\
\text { Technologies }\end{array}$ \\
\hline
\end{tabular}


$1 \quad$ Fluxapyroxad Haptens and Antibodies for Highly Sensitive Immunoanalysis of Food Samples

5 Josep V. Mercader ${ }^{\dagger}$, Antonio Abad-Somovilla ${ }^{\ddagger}$, Consuelo Agulló ${ }^{\ddagger}$, Antonio AbadFuentes $^{\dagger, *}$

7

8

$9{ }^{b}$ Department of Biotechnology, Institute of Agrochemistry and Food Technology (IATA),

10 Spanish National Research Council (CSIC), Agustí Escardino 7, 46980 Paterna, València, Spain

$11{ }^{a}$ Department of Organic Chemistry, Universitat de València, Doctor Moliner 50, 46100

12 Burjassot, València, Spain

13 * Corresponding author (Tel. +34-963900022; Fax+34-963636301; E-mail: aabad@iata.csic.es). 
14 Abstract

15 Fluxapyroxad is a new-generation carboxamide fungicide, with residues increasingly 16 being found in food samples. Immunochemical assays have gained acceptance in food

17 quality control as rapid, cost-effective, sensitive, and selective methods for large sample throughput and in situ applications. In the present study, immunoreagents to fluxapyroxad were obtained for the first time, and competitive immunoassays were developed for the sensitive and specific determination of fluxapyroxad residues in food samples. Two carboxyl-functionalized analogues of fluxapyroxad were prepared and antibodies with $\mathrm{IC}_{50}$ values in the low nanomolar range were generated from both haptens, though a dissimilar response was observed concerning specificity. A robust direct assay was set up, with a calibration curve exhibiting a limit of detection of 0.05 $\mathrm{nM}(0.02 \mu \mathrm{g} / \mathrm{L})$. Limits of quantitation of $5 \mu \mathrm{g} / \mathrm{L}$ were obtained for peach, apple, and grape juices using samples diluted in water. The direct immunoassay was also

27 successfully applied to the determination of fluxapyroxad in grapes from in-field treated grapevines.

\section{Keywords}

Fungicide, ELISA, antibody, food safety, chemical residue 
INTRODUCTION

Fluxapyroxad is a new-generation broad-spectrum fungicide that belongs to the pyrazole carboxamide class of active biocides. It stunts spore germination as well as germ tube and mycelium growth in the target species via inhibition of the succinate dehydrogenase (SDH) activity in complex II of the mitochondrial respiratory chain, which catalyses the oxidation of succinate to fumarate by reducing ubiquinone to ubiquinol. This enzyme is involved in two essential metabolic pathways, i.e., the oxidative phosphorylation and the Krebs cycle, which makes SDH an excellent target for fungi control. This particular and effective mode of action converts SDH inhibitors into outstanding candidates for co-formulation with other fungicides in order to prevent the emergence of resistance. ${ }^{1-4}$ The 2014 global market for SDH-inhibitor fungicides was valued at $\$ 2721$ million, and it is expected to grow at a compound annual growth rate of $7.1 \%$ to mature into a $\$ 4046.6$ million market by $2020 .^{5}$

Fluxapyroxad (Figure 1) was recently developed on the basis of the molecular structure of boscalid, the most successful SDH inhibitor to date, by systematically modifying different parts of the molecule. ${ }^{6}$ It displays low acute toxicity to humans by the oral, dermal, and inhalation routes; it is not irritating to the eyes and skin and is classified as "not likely to be carcinogenic". The $\mathrm{LD}_{50}$ in rats treated orally or dermally with fluxapyroxad was greater than $2000 \mathrm{mg} / \mathrm{kg}$ of body weight. Low harm to terrestrial organisms was found; however, acute risk to estuarine/marine species could occur if formulations of fluxapyroxad were applied in areas that may result in spray drift to such environments. ${ }^{7-9}$ Because of its environmental and health safety, as well 
54 as its prominent pesticide efficiency, fluxapyroxad and other SDH inhibitor fungicides

55

56

57 are deemed outstanding candidates for fungal disease control in the near future.

Gas and high-performance liquid chromatography coupled to different sorts of detectors are the most common analytical methods that are employed nowadays for chemical residue as well as contaminant detection. These are extremely sensitive and selective techniques, especially when coupled to mass spectrometers, and constitute the methods of choice for large monitoring programmes for which an extraordinary multiresidue capacity is demanded. ${ }^{10}$ Nevertheless, other analytical applications, such as toxicological crisis, industrial control departments, dissipation and transfer studies, or just personal assessment, require straightforward, low cost, and rapid procedures for which the immunochemical methods provide a powerful alternative approach. ${ }^{11-13}$ Antibody-based techniques are very selective and highly sensitive, and can be developed in a variety of immunoassay formats. Undoubtedly, the competitive enzyme-linked immunosorbent assay (CELISA) is the most common immunochemical method, probably due to its large sample throughput as well as its ability to provide quantitative results.

In order to develop a novel cELISA procedure, three immunoreagents are needed: the immunizing conjugate, the antibody, and the assay conjugate. The two required conjugates generally consist of a protein to which a functionalized derivative mimicking the target analyte, called a hapten, is linked. This synthetic molecule is usually prepared with a spacer arm holding a functional chemical group for covalent coupling. Rational design of different functionalized derivatives constitutes a key step for high-affinity and specific antibody generation as well as immunoassay 
77 development. ${ }^{14}$ Haptens that are employed for the preparation of immunizing conjugates should preferentially display the characteristic moieties and preserve the electronic distribution and conformation of the target compound. ${ }^{15}$ However, the optimum linker tethering site is usually difficult to predict, and intricate synthetic procedures are most commonly required in order to prepare alternative immunizing haptens. ${ }^{16}$ On the other hand, it is well established that employing heterologous haptens, i.e. molecules that are different from the immunizing hapten, in cELISA can improve the sensitivity of the assay and even modulate the selectivity of polyclonal antibody-based immunoassays. ${ }^{17,18}$ Hapten heterologies most commonly consist of changes in the immunodeterminant moieties of the target molecule or a different linker composition or tethering site. These strategies have been shown to be quite effective, particularly in the conjugate-coated assay format. ${ }^{19-21}$ Nevertheless, further studies are required aiming to increase the scientific knowledge about the structureimmunogenicity and structure-assay activity relationships of haptens.

In this study, we developed for the first time high-affinity antibodies specific to fluxapyroxad. In order to reach this goal, we investigated the influence of two proximate linker tethering sites over the generation of antibodies and their use as heterologous haptens. With this aim, polyclonal antibodies were raised since they are better representatives of the immune response. Finally, alternative cELISA procedures were developed, and their applicability to the analysis of residues of this agrochemical in food samples was evaluated.

\section{MATERIALS AND METHODS}


Reagents and Instruments. Technical fluxapyroxad was generously provided by BASF (Ludwigshafen, Germany) and Pestanal grade of fluxapyroxad and other pesticide standards were purchased from Sigma/Aldrich (Madrid, Spain). Compounds employed in this work only present slight safety concerns. Nevertheless, working in a wellventilated fume hood is advisable for synthesis work. Bovine serum albumin (BSA) fraction V was from Roche Applied Science (Mannheim, Germany). Ovalbumin (OVA), horseradish peroxidase (HRP), and adult bovine serum (ABS) were purchased from Sigma/Aldrich (Madrid, Spain). Sephadex G-25 HiTrap Desalting columns (GE Healthcare, Uppsala, Sweden) were utilized for protein-hapten conjugate purification. Goat anti-rabbit immunoglobulin polyclonal antibody conjugated to peroxidase was from BioRad (Madrid, Spain). Costar flat-bottom high-binding 96-well polystyrene ELISA plates were from Corning (Corning, NY). UV-Vis spectra of haptens and conjugates as well as ELISA absorbances were read with a PowerWave HT from BioTek Instruments (Winooski, VT). Microwells were washed with an ELx405 microplate washer also from BioTek Instruments.

Preparation of Hapten FXn. The schematic representation of the synthesis of hapten FXn is depicted in Figure 2.

Synthesis of ethyl 1-allyl-3-(difluoromethyl)-1H-pyrazole-4-carboxylate, 2. $\mathrm{K}_{2} \mathrm{CO}_{3}$ (278 mg, $2.012 \mathrm{mmol}, 1.5$ equiv) and allyl bromide (174 $\mu \mathrm{L}, 2.012 \mathrm{mmol}, 1.5$ equiv) were added to a suspension of ethyl 3-(difluoromethyl)-1H-pyrazole-4-carboxylate, 1 (254.9 $\mathrm{mg}, 1.341 \mathrm{mmol}$ ) in dry acetone $(3 \mathrm{~mL})$ under nitrogen. The resulting mixture was stirred at room temperature for $4 \mathrm{~h}$, then diluted with water and extracted with EtOAc. The combined organic layers were washed with brine and dried over anhydrous 
$122 \mathrm{MgSO}_{4}$, filtered, and concentrated under vacuum. The residue obtained was purified

123 by flash chromatography performed on silica gel 60, 230-400 mesh (Merck,

124 Darmstadt, Germany), using hexane/EtOAc mixtures from 9:1 to 8:2 as eluent, to give 125 allyl derivative 2 as an oil (216.3 $\mathrm{mg}, 70 \%)$. ethyl ester $2(215.2 \mathrm{mg}, 0.934 \mathrm{mmol})$ in a mixture of $1 \mathrm{M}$ aqueous $\mathrm{NaOH}(4 \mathrm{~mL})$ and $\mathrm{EtOH}(3 \mathrm{~mL}$ ) was stirred at room temperature for $2 \mathrm{~h}$ (reaction monitored by thin layer chromatography on F254 silica gel plates, hexane/EtOAc 1:1). The reaction mixture was diluted with water, acidified to $\mathrm{pH}$ 3-5 with citric acid, and extracted with EtOAc. 
aqueous solution of $\mathrm{NaHCO}_{3}$ and brine, dried over anhydrous $\mathrm{MgSO}_{4}$, filtered, and concentrated under vacuum. The residue obtained was purified by chromatography, using hexane/EtOAc mixtures from 9:1 to 6:4 as eluent, to give, in order of elution, unreacted 2-aminobiphenyl 4 (10.1 mg, 4.9\%) and amide 5 (324.7 mg, 90.7\% based on recovered starting material) as a white solid.

$$
\text { Synthesis of 6-(3-(difluoromethyl)-4-((3',4',5'-trifluoro-[1,1'-biphenyl]-2- }
$$

yl)carbamoyl)-1H-pyrazol-1-yl)hex-4-enoic acid, 6. But-3-enoic acid (52.8 mg, $52.2 \mu \mathrm{L}$, $0.615 \mathrm{mmol}, 3$ equiv) was added to a suspension of $5(83.4 \mathrm{mg}, 0.205 \mathrm{mmol}), 2 \mathrm{nd}$ Generation Grubbs Catalyst [(1,3-bis(2,4,6-trimethylphenyl)-2imidazolidinylidene)dichloro(phenylmethylene)(tricyclohexylphosphine) ruthenium] (10.5 mg, $0.012 \mathrm{mmol}, 0.06$ equiv) and Cul $(3.0 \mathrm{mg}, 0.016 \mathrm{~mol}, 0.08$ equiv) in anhydrous $\mathrm{Et}_{2} \mathrm{O}(2.4 \mathrm{~mL})$ under nitrogen. The resulting mixture was stirred at $60{ }^{\circ} \mathrm{C}$ for $6 \mathrm{~h}$ under microwave irradiation (300 W). After this time, the solvent was evaporated under vacuum and the residue obtained was purified by chromatography. Elution, first with $\mathrm{CH}_{2} \mathrm{Cl}_{2}$ and then with $\mathrm{CH}_{2} \mathrm{Cl}_{2}-\mathrm{Et}_{2} \mathrm{O}$ 9:1, gave unreacted starting material 5 (24.8 mg). Further elution, first with $\mathrm{CHCl}_{3}$ and then with $\mathrm{CHCl}_{3} / \mathrm{MeOH} 9: 1$, afforded the corresponding cross-metathesis product $6(44.8 \mathrm{mg}, 66.8 \%$ based on recovered starting material) as an approximately 8:2 mixture of $E / Z$ geometrical isomers.

$$
\text { Synthesis of 6-(3-(difluoromethyl)-4-((3',4',5'-trifluoro-[1,1'-biphenyl]-2- }
$$
yl)carbamoyl)-1H-pyrazol-1-yl)hexanoic acid (Hapten FXn). A solution of geometric isomers of alkene $6(37.3 \mathrm{mg}, 0.08014 \mathrm{mmol})$ in a mixture of $10 \% \mathrm{Pd} / \mathrm{C}(20 \mathrm{mg})$ in EtOAc $(1.9 \mathrm{~mL})$ was hydrogenated under a hydrogen pressure of 3 atm for $4 \mathrm{~h}$. The black suspension was filtered through a pad of Celite with EtOAc, the filtrate was 
168

169

170

171

172

173

174

175

176

177

178

179

180

181

182

183

184

185

186

187

188

189

190

concentrated in vacuum, and the residue was purified by chromatography, using

$\mathrm{CHCl}_{3} / \mathrm{MeOH}$ 95:5 as eluent, to give hapten $\mathrm{FXn}(29.6 \mathrm{mg}, 79 \%)$ as a white solid, m.p.

132.6-133.8 ${ }^{\circ} \mathrm{C}$ (crystals obtained from slow evaporation from $\mathrm{CHCl}_{3}$ solution). IR (neat) $v_{\max }\left(\mathrm{cm}^{-1}\right): 3500-2500(\mathrm{br}, \mathrm{s}), 3423(\mathrm{w}), 3257(\mathrm{~m}), 3127(\mathrm{w}), 2952(\mathrm{w}), 1710$

(m), $1654(\mathrm{~m}), 1617$ (m), 1545 (s), 1045 (s), 760 (s). ${ }^{1} \mathrm{H}-\mathrm{NMR}\left(300 \mathrm{MHz}, \mathrm{CDCl}_{3}\right) \delta(\mathrm{ppm})$ : $8.16(1 \mathrm{H}, \mathrm{d}, J=8.2 \mathrm{~Hz}, \mathrm{H}-3 \mathrm{BiPh}), 8.04(1 \mathrm{H}, \mathrm{s}, \mathrm{H}-5 \mathrm{Pz}), 7.86(1 \mathrm{H}, \mathrm{br} t, J=3.5 \mathrm{~Hz}, \mathrm{NH})$, 7.50-7.36 (1H, m, H-4 BiPh), 7.25-7.19 (2H, m, H-5 and H-6 BiPh), 7.06-6.94 (2H, m, H$2^{\prime}$ and $\left.\mathrm{H}-6^{\prime} \mathrm{BiPh}\right), 6.65\left(1 \mathrm{H}, \mathrm{t}, J=54.2 \mathrm{~Hz}, \mathrm{CHF}_{2}\right), 4.13(2 \mathrm{H}, \mathrm{d}, J=7.1 \mathrm{~Hz}, \mathrm{H}-5), 2.39(2 \mathrm{H}, \mathrm{t}$, $J=7.2 \mathrm{~Hz}, \mathrm{H}-2), 2.00-1.86(2 \mathrm{H}, \mathrm{m}, \mathrm{H}-4), 1.74-1.56(2 \mathrm{H}, \mathrm{m}, \mathrm{H}-3) .{ }^{19} \mathrm{~F}-\mathrm{NMR}(282 \mathrm{MHz}$, $\left.\mathrm{CDCl}_{3}\right) \delta(\mathrm{ppm}):-109.0\left(2 \mathrm{~F}, \mathrm{~s}, \mathrm{CHF}_{2}\right),-134.2\left(2 \mathrm{~F}, \mathrm{~d}, J=20.6 \mathrm{~Hz}, \mathrm{~F}-3^{\prime}\right.$ and F-5' BiPh), $-162.0\left(1 \mathrm{~F}, \mathrm{t}, J=20.6 \mathrm{~Hz}, \mathrm{~F}-4{ }^{\prime} \mathrm{BiPh}\right) .{ }^{13} \mathrm{C}-\mathrm{NMR}\left(75 \mathrm{MHz}, \mathrm{CD}_{3} \mathrm{D}\right) \delta(\mathrm{ppm}) 176.9\left(\mathrm{CO}_{2} \mathrm{H}\right)$, $163.1(\mathrm{CONH}), 152.2\left(\mathrm{ddd}, J=248.8,10.2,4.5 \mathrm{~Hz}, \mathrm{C}-3^{\prime}\right.$ and $\left.\mathrm{C}-5^{\prime} \mathrm{BiPh}\right), 147.0(\mathrm{t}, J=24.7$ $\mathrm{Hz}, \mathrm{C}-3 \mathrm{Pz}$ ), 140.3 (dt, J = 250.0, 15.4 Hz, C-4' BiPh), 137.3 (td, J = 8.5, 5.1 Hz, C-1' BiPh), 137.0 (C-2 BiPh), 135.2 (C-1 BiPh), 133.4 (C-5 Pz), 131.4 (C-4 BiPh), 130.2 (C-5 BiPh), 128.8 (C-3 BiPh), 128.4 (C-6 BiPh), 116.7 (C-4 Pz), 114.3 (dd, J=14.6, 6.8 Hz, C-2' and C6' BiPh), 111.2 (t, J = 235.1 Hz, $\mathrm{CHF}_{2}$ ), 53.5 (C-5), 34.1 (C-2), 30.4 (C-4), 22.9 (C-3). HRMS (TOF MS ES+): $\mathrm{m} / z$ calcd for $\mathrm{C}_{22} \mathrm{H}_{19} \mathrm{~F}_{5} \mathrm{~N}_{3} \mathrm{O}_{3}[\mathrm{M}+\mathrm{H}]^{+}$468.1341, found 468.1340.

Preparation of Hapten FXc. The schematic representation of the synthesis of hapten FXc is depicted in Figure 3.

Synthesis of 3-(dibromomethyl)-1-methyl-N-(3',4',5'-trifluoro-[1,1'-biphenyl]-2-yl)1H-pyrazole-4-carboxamide, 7. A solution $1 \mathrm{M}$ of $\mathrm{BBr}_{3}$ in $\mathrm{CH}_{2} \mathrm{Cl}_{2}(3.15 \mathrm{~mL}, 3.15 \mathrm{mmol}, 6$ equiv) was dropwise added to a solution of fluxapyroxad (200 $\mathrm{mg}, 0.525 \mathrm{mmol}$ ) in anhydrous $\mathrm{CH}_{2} \mathrm{Cl}_{2}(8 \mathrm{~mL})$ at $-78{ }^{\circ} \mathrm{C}$ under nitrogen. The reaction mixture was allowed to 
191 warm slowly to room temperature and was stirred for $4 \mathrm{~h}$. The mixture was then 192 cooled to $0{ }^{\circ} \mathrm{C}$, then carefully quenched with water and extracted with $\mathrm{CH}_{2} \mathrm{Cl}_{2}$. The 193 combined organic extracts were washed with brine, dried over anhydrous $\mathrm{MgSO}_{4}$, and 194 concentrated under reduced pressure to give dibromide 7 ( $251 \mathrm{mg}, 95.1 \%$ ) as a solid, 195 which was deemed sufficiently pure to be used in the next step without any further 196 purification.

Synthesis of 3-formyl-1-methyl-N-(3',4',5'-trifluoro-[1,1'-biphenyl]-2-yl)-1H-pyrazole4-carboxamide, 8. A solution of dibromide $7(182 \mathrm{mg}, 0.362 \mathrm{mmol})$ in anhydrous pyridine $(500 \mu \mathrm{L})$ was stirred at $100{ }^{\circ} \mathrm{C}$ under nitrogen for $90 \mathrm{~min}$. The resulting mixture was cooled and poured into ice-cold water and extracted with EtOAc, the combined organic layers were washed with water and brine and dried over anhydrous $\mathrm{MgSO}_{4}$.

202 Evaporation of the solvent under reduced pressure and filtration through a small plug 203 of silica gel, washing with $\mathrm{CH}_{2} \mathrm{Cl}_{2}$ /EtOAc 9:1, afforded nearly pure aldehyde 8 (118.5 mg, 91\%).

Synthesis of (E/Z)-6-(1-methyl-4-((3',4',5'-trifluoro-[1,1'-biphenyl]-2-yl)carbamoyl)1H-pyrazol-3-yl)hex-5-enoic acid, 9. A suspension of 5-(triphenylphosphonio)pentanoic acid bromide (144.5 $\mathrm{mg}, 0.326 \mathrm{mmol}, 2$ equiv) in anhydrous hexamethylphosphoramide $(442 \mu \mathrm{L})$ and THF $(600 \mu \mathrm{L})$ was sonicated at room temperature under nitrogen until a clear solution was obtained. Then, a $0.5 \mathrm{M}$ solution

210 of potassium hexamethyldisilazide in toluene $(1.32 \mathrm{~mL}, 0.660 \mathrm{mmol}, 4$ equiv) was dropwise added under the same conditions to obtain a deep orange solution of the corresponding Wittig reagent (ylide). The above mixture was cooled with stirring in an

213 ice-water bath, and then a solution of aldehyde $8(58.6 \mathrm{mg}, 0.163)$ in anhydrous THF 
$214(600 \mu \mathrm{L})$ was added via cannula. After $1.5 \mathrm{~h}$, the reaction mixture was poured into ice-

215 water, acidified to $\mathrm{pH} \mathrm{2-3} \mathrm{with} 1 \mathrm{M} \mathrm{HCl}$ and extracted with EtOAc. The combined

216 organic layers were washed with a saturated aqueous solution of $\mathrm{LiCl}$ and brine, dried

217 over anhydrous $\mathrm{MgSO}_{4}$, and concentrated under reduced pressure to give an oily

218 residue (193 $\mathrm{mg}$ ) that was purified by chromatography, using $\mathrm{CHCl}_{3} / \mathrm{MeOH}$ mixtures

219 from 100:0 to $95: 5$ as eluent, to afford alkene 9 (49.2 mg, 68\%) as a thick oil. According

220 to its ${ }^{1} \mathrm{H}$-NMR spectrum, it was a ca. 3:2 mixture of $E$ - and Z-isomers of the double 221 bond.

Synthesis of 6-(1-methyl-4-((3',4',5'-trifluoro-[1,1'-biphenyl]-2-yl)carbamoyl)-1Hpyrazol-3-yl) hexanoic acid (Hapten FXc). To a solution of 9 (44.8 mg, $0.101 \mathrm{mmol}$ ) in EtOAc $(2 \mathrm{ml})$ was added $\mathrm{Pd} / \mathrm{C}(10 \%, 23 \mathrm{mg})$ and the mixture was hydrogenated at 3 atm for $4.5 \mathrm{~h}$. The catalyst was filtered through a pad of silica gel and the filter cake was washed with EtOAc. The combined filtrates were concentrated under vacuum to give hapten FXc (41.2 mg, 92.6\%) as a white solid, m.p. $104.4-105.8{ }^{\circ} \mathrm{C}$ (from hexane/EtOAc/ $\mathrm{CHCl}_{3}$ ). IR (neat) $v_{\max }\left(\mathrm{cm}^{-1}\right):$ 2500-3350 (br, s), $3331(\mathrm{~s}), 3122(\mathrm{w}), 3073$ (w), 2945 (m), 1741 (s), 1697 (s), 1670 (s), 1615 (s), 1532 (s), 1489 (s), 1425 (s), 1207 (s), 1038 (s), 760 (s). ${ }^{1} \mathrm{H}-\mathrm{NMR}\left(300 \mathrm{MHz}, \mathrm{CDCl}_{3}\right) \delta(\mathrm{ppm}): 8.20(1 \mathrm{H}, \mathrm{d}, J=8.2 \mathrm{~Hz}, \mathrm{H}-3$ BiPh), $7.50(1 \mathrm{H}, \mathrm{s}, \mathrm{H}-5 \mathrm{Pz}), 7.48-7.36$ (1H, m, H-4 BiPh), 7.25-7.12 (3H, m, H-5 and H-6 BiPh and $\mathrm{NH}), 7.12-6.93\left(2 \mathrm{H}, \mathrm{m}, \mathrm{H}-2^{\prime}\right.$ and $\left.\mathrm{H}-6^{\prime} \mathrm{BiPh}\right), 3.83(3 \mathrm{H}, \mathrm{s}, \mathrm{NMe}), 2.67(2 \mathrm{H}, \mathrm{t}, J=$ 7.5, H-6), $2.33(2 \mathrm{H}, \mathrm{t}, 2 \mathrm{H}, \mathrm{t}, J=7.5, \mathrm{H}-2), 1.64(4 \mathrm{H}$, quint, $J=7.5, \mathrm{H}-3$ and $\mathrm{H}-5), 1.35(2 \mathrm{H}$, $\mathrm{m}, \mathrm{H}-4) .{ }^{19} \mathrm{~F}-\mathrm{NMR}\left(282 \mathrm{MHz}, \mathrm{CDCl}_{3}\right) \delta(\mathrm{ppm}):-133.0\left(2 \mathrm{~F}, \mathrm{~d}, J=20.6 \mathrm{~Hz}, \mathrm{~F}-3^{\prime}\right.$ and F-5' BiPh), $-160.9\left(1 \mathrm{~F}, \mathrm{t}, J=20.6 \mathrm{~Hz}, \mathrm{~F}-4^{\prime} \mathrm{BiPh}\right) .{ }^{13} \mathrm{C}-\mathrm{NMR}\left(75 \mathrm{MHz}, \mathrm{CDCl}_{3}\right) \delta$ (ppm): 178.6 $\left(\mathrm{CO}_{2} \mathrm{H}\right), 161.4(\mathrm{CONH}), 153.0$ (C-3 Pz), 151.6 (ddd, J = 252.3, 10.0, 4.1 Hz, C-3' and C-5' BiPh), 139.5 (dt, J = 253.7, 14.9 Hz, C-4' BiPh), 134.5 (td, J = 7.7, 5.0 Hz, C-1' BiPh), 
134.7 (C-2 BiPh), 131.9 (C-5 Pz), 130.2 (C-1 BiPh), 131.1 (C-1 BiPh), 130.1 (C-6 BiPh), 129.7 (C-4 BiPh), 125.0 (C-5 BiPh), 123.2 (C-3 BiPh), 115.4 (C-4 Pz), 113.8 (dd, J = 14.6, $6.8 \mathrm{~Hz}, \mathrm{C}-2^{\prime}$ and C-6' BiPh), 39.2 (NMe), 33.9 (C-2), 28.9 (C-4), 28.2 (C-6), 27.5 (C-5), 24.5 (C-3). HRMS (TOF MS ES+): $m / z$ calcd for $\mathrm{C}_{23} \mathrm{H}_{23} \mathrm{~F}_{3} \mathrm{~N}_{3} \mathrm{O}_{2}[\mathrm{M}+\mathrm{H}]^{+} 446.1686$, found 446.1681.

Preparation of Protein Conjugates. The synthesis of $N$-hydroxysuccinimidyl esters of haptens FXn and FXc (Figures 2 and 3) was performed by reaction of the purified hapten with $\mathrm{N}, \mathrm{N}^{\prime}$-disuccinimidyl carbonate and $\mathrm{Et}_{3} \mathrm{~N}$ in anhydrous $\mathrm{CH}_{3} \mathrm{CN}$. Both haptens were covalently linked to BSA, OVA, and HRP using a 24,8 , and 5.5 molar excess, respectively, of the corresponding purified $\mathrm{N}$-hydroxysuccinimidyl ester according to previously established procedures. ${ }^{22}$ The obtained hapten-to-protein molar ratio (MR) of the prepared conjugates was determined by MALDI-TOF mass spectrometry.

Antibody Generation. Procedures for animal immunization were approved by the Ethics Committee of the University of Valencia for Animal Experimentation and Welfare. Animal manipulation was carried out according to Spanish and European laws and guidelines concerning the protection of animals used for scientific purposes (RD 1201/2005, Law 32/2007, and European Directive 2010/63/EU). Two white female rabbits of around $2 \mathrm{~kg}$ each were subcutaneously immunized with $300 \mu \mathrm{g}$ of BSA-FXn or BSA-FXC conjugate in a 1:1 emulsion between phosphate buffer solution and Freund's adjuvant (complete for the first injection and incomplete for further boosts). The immunogen was given 4 times with 21-day intervals. Whole blood was taken $10 \mathrm{~d}$ after the fourth injection and it was allowed to coagulate overnight at $4{ }^{\circ} \mathrm{C}$. The serum 
261 was separated by centrifugation and antibodies were precipitated twice with 1 volume

262 of a saturated ammonium sulfate solution. Precipitated antisera were stored at $4{ }^{\circ} \mathrm{C}$,

263 and a working antibody solution was prepared by 4-fold dilution with PBS containing

$2641 \%(w / v)$ BSA and kept at $4{ }^{\circ} \mathrm{C}$.

265 Immunoassay Development. Immunoassays were developed using the antibody-

266 coated direct format and the conjugate-coated indirect format according to previously

267 published procedures. ${ }^{23}$ Starting from a $10 \mu \mathrm{M}$ fluxapyroxad solution in PBS, eight-

268 point fluxapyroxad standard curves, including a blank, were prepared by 10 -fold serial

269 dilution in PBS. A $10 \mathrm{mM}$ fluxapyroxad stock solution in anhydrous $\mathrm{N}, \mathrm{N}$ -

270 dimethylformamide was used to prepare the first standard solution. For sample

271 analysis, fruit juices were purchased from local supermarkets. The competitive

272 reaction was carried out with samples diluted in MilliQ water and the corresponding

273 immunoreagent in $2 \times$ PBS containing $0.05 \%(v / v)$ Tween 20 . In order to ascertain the

274 minimum sample dilution to obtain a reliable determination of fluxapyroxad, the

275 analytical parameters of the standard curves prepared in the diluted matrices were

276 compared to those from curves run in water. Recovery studies with fluxapyroxad

277 fortified fruit samples were performed in order to examine the accuracy and precision

278 of the developed immunoassays. Each sample was analyzed in duplicate wells and

279 average absorbance values were interpolated into the standard curve run in triplicate

280 wells in the same plate.

281 Data Treatment. Microplates were read at $492 \mathrm{~nm}$ using $650 \mathrm{~nm}$ as reference 282 wavelength with a PowerWave HT instrument (BioTek, Winooski, VT). Experimental 283 values were fitted to a four-parameter logistic equation using the SigmaPlot software 
package from SPSS Inc. (Chicago, IL). Assay sensitivity was defined as the concentration of analyte at the inflection point of the fitted curve. This value typically corresponds to a $50 \%$ reduction $\left(\mathrm{IC}_{50}\right)$ of the maximum absorbance $\left(\mathrm{A}_{\max }\right)$. The limit of detection (LOD) and the dynamic range of the assay were estimated as the concentration of analyte providing a decrease of $A_{\max }$ of $10 \%$ and between $20 \%$ and $90 \%$, respectively. Crossreactivity was determined as the percentage of the quotient between the $\mathrm{IC}_{50}$ value for fluxapyroxad and the $\mathrm{IC}_{50}$ value for the evaluated compound.

Sample Preparation. Peach, apple, and grape juices were obtained from local supermarkets. In order to obtain contaminated samples, grapevines were treated with a commercial formulation kindly provided by BASF Crop Protection (Sercadis, fluxapyroxad $300 \mathrm{~g} / \mathrm{L}$ ) at the dose recommended by the manufacturer using a manual sprayer. Three days after the treatment, grape samples (500 g) were harvested, and upon arrival at the laboratory berries were separated from the stems, homogenized using a T-25 Ultra-Turrax blender (IKA, Staufen, Germany), and stored in polypropylene tubes at $-20^{\circ} \mathrm{C}$ until analysis. The QuEChERS method was employed for extraction of fungicide residues from samples. ${ }^{24}$ Briefly, homogenized grapes (5 g) were introduced into $50 \mathrm{~mL}$ polypropylene centrifuge tubes containing $0.5 \mathrm{~g}$ of sodium acetate and 2.0 $\mathrm{g}$ of anhydrous magnesium sulfate. Samples were then extracted by vortexing for 1 min with $5 \mathrm{~mL}$ of $1 \%(\mathrm{v} / \mathrm{v})$ acetic acid in acetonitrile containing $500 \mu \mathrm{g} / \mathrm{L}$ of triphenylphosphate as internal standard, and centrifuged for $5 \mathrm{~min}$ at $2200 \times \mathrm{g}$. The extracts $(1 \mathrm{~mL})$ were then cleaned-up with $50 \mathrm{mg}$ of PSA (primary-secondary amine) and $150 \mathrm{mg}$ of anhydrous magnesium sulfate, vortexed for $1 \mathrm{~min}$, and centrifuged 5 min at 6700xg. Purified extracts were then filtered through a $0.22 \mu \mathrm{m}$ Teflon filter and 
analyzed by the optimized cELISA and by ultra-performance liquid chromatography coupled to a triple quadrupole tandem mass spectrometer (UPLC-MS/MS).

Chromatographic analysis. Determinations were carried with an Acquity UPLC system (Waters, Milford, MA) equipped with a $50 \mathrm{~mm} \times 2.1 \mathrm{~mm}$ i.d., $1.7 \mu \mathrm{m}$, Bridged Ethylene Hybrid C18 column. The injection volume was $5 \mu \mathrm{L}$ and the mobile phase consisted of $0.5 \%(\mathrm{v} / \mathrm{v})$ formic acid in water $(\mathrm{A})$ and acetonitrile $(\mathrm{B})$. The elution gradient started at $50 \%$ of $B$ at a flow-rate of $400 \mu \mathrm{L} / \mathrm{min}$, and then $B$ was linearly increased to $95 \%$ in $4 \mathrm{~min}$. The obtained retention times, using the aforementioned conditions, were 1.36 and $2.36 \mathrm{~min}$ for fluxapyroxad and triphenylphosphine as internal standard, respectively. Tandem mass acquisitions were performed in a Waters Acquity triple quadrupole mass spectrometry detector, equipped with a Z-spray electrospray ionization source, with $3.5 \mathrm{kV}$ capillary voltage, at $120{ }^{\circ} \mathrm{C}$ as source temperature, and $300{ }^{\circ} \mathrm{C}$ as desolvation temperature. The employed parameters were: ESI+, parent ion $m / z$ 382.0, daughter ions $m / z 314.3$ and 342.3, 30 eV collision energy, and $20 \mathrm{~V}$ cone energy for fluxapyroxad; and $\mathrm{ESI}+$, parent ion $\mathrm{m} / \mathrm{z} 328.3$, daughter ions $\mathrm{m} / \mathrm{z} 77.0$ and 152.4, $30 \mathrm{eV}$ collision energy, and $25 \mathrm{~V}$ cone energy for 323 triphenylphosphine.

\section{RESULTS AND DISCUSSION}

Hapten Synthesis. Two functionalized haptens mimicking fluxapyroxad were designed, namely haptens FXn and FXc (Figures 2 and 3). Both haptens incorporate a spacer arm suitable for protein conjugation, namely a carboxylated hydrocarbon linear chain, in complementary positions of the pyrazole ring. The spacer arm in hapten FXn was a substituent of the methyl group at $\mathrm{N}-1$ which would produce an insignificant 
330 effect on the electronic distribution and conformational mobility of the fluoxapyroxad

331 framework. In the case of hapten FXc, the incorporation of the alkyl chain as a C-3

332 substituent of the difluoromethyl group would entail a greater change, both in the 333 electronic distribution of the pyrazole ring and in the conformational disposition of the amide group, due to the weak electron-donor effect of the alkyl chain compared to the withdrawing electron effect of the difluoromethyl group and the greater steric hindrance introduced by the highly flexible linear hydrocarbon spacer arm.

The preparation of hapten FXn is outlined in Figure 2. The synthesis began with the incorporation of an allyl group at the $\mathrm{N}-1$ position of ethyl $1 \mathrm{H}$-pyrazole-4-carboxylate $\mathbf{1}$, which was used as both a blocking group of this position during the construction of the fluxapyroxad framework and as a pivotal moiety for the subsequent elaboration of the hydrocarbon chain constituting the spacer arm. Thus, alkylation of 1 with allyl bromide under basic conditions led to allyl ether $\mathbf{2}$, whose ethyl ester moiety was hydrolyzed under conventional basic conditions to afford pyrazole carboxylic acid 3. Activation of the carboxylate group to the acid chloride, by treatment with phosphorus pentachloride in ether at room temperature, followed by reaction with biphenyl amine

4 in the presence of pyridine, to quench the acid $(\mathrm{HCl})$ formed, led to amide 5 , thus completing the part of the hapten skeleton common with the parent analyte. Elaboration of the $\mathrm{C} 5$ carboxylated chain at $\mathrm{N}-1$ from 5 was carried out via a microwave irradiation promoted cross-metathesis reaction of the allyl ether moiety with but-3-enoic acid catalyzed by Grubbs' second generation catalyst and copper iodide as co-catalyst. The cross-metathesis reaction afforded alkene acid 6 as a ca. 8:2 mixture of $E / Z$ geometrical isomers of the double bond that was hydrogenated under heterogeneous catalyzed conditions to give the desired hapten. The synthesis of 
354 hapten FXn was thus completed from pyrazole 1 in six synthetic steps and 31\% overall 355 yield.

356 On the other hand, the synthesis of hapten FXc was initiated from fluxapyroxad and 357 involved the initial transformation of the difluoromethyl group into a dibromomethyl 358 group (Figure 3), which underwent hydrolysis to a formyl group by heating in pyridine 359 and subsequent aqueous workup to afford aldehyde 8 . The elaboration of the 360 carboxylated spacer arm was carried out, in this case, through a Wittig olefination 361 reaction between the aldehyde carbonyl group of 8 and the ylide derived from (4362 carboxybutyl)triphenylphosphonium bromide and potassium hexamethyldisilazane, 363 which afforded the olefinic acid 9 as a ca. 3:2 mixture of trans and cis isomers, 364 followed by catalytic hydrogenation of the generated double bond. The synthesis of 365 hapten FXc was thus achieved in four steps with an excellent $63 \%$ overall yield from 366 fluxapyroxad.

367 Immunoreagent Preparation. The same coupling procedure, the active ester method, was applied for preparation of both the immunizing and the assay conjugates.

369 Previously, the carboxyl functional group of each hapten was activated under smooth conditions with $N, N^{\prime}$-disuccinimidyl carbonate, which allowed the easy isolation and 371 further chromatographic purification of the corresponding active esters, FXn-NHS and 372 FXc-NHS esters (Figures 2 and 3). Freshly prepared and purified succinimidyl esters of 373 haptens were used for covalently coupling to BSA, OVA, and HRP. Since the pure active ester was employed, no succinimide and carbodiimide were present during the coupling reaction; thus, no secondary and cross-coupling reactions could occur and 376 higher coupling yields could be accomplished, so lower amounts of hapten were 
377 required. The obtained hapten-to-protein molar ratios (MR), determined by MALDI-

378 TOF mass spectrometry, for BSA, OVA, and HRP conjugates were 18.9, 5.3, and 1.2 and

15.2, 5.4 and 1.3 for haptens FXn and FXc, respectively (Figure 4). These values are within the optimum range of MR values for immunizing and assay conjugates.

Four rabbits were immunized; two with conjugate BSA-FXn and two with conjugate BSA-FXc. Thus, two polyclonal antibodies, named FXn\#1 and FXn\#2, were obtained from the conjugate of hapten FXn, and two, named FXc\#1 and FXc\#2, from the conjugate of hapten FXc.

Antibody Characterization. Specificity of the antibodies was assessed by indirect cELISA using the homologous coating conjugate. All of the generated polyclonals were highly specific of fluxapyroxad. Inhibition was negligible even with a concentration of $10 \mu \mathrm{M}$ of other SDH-inhibitor fungicides (penthiopyrad and fluopyram) as well as other widely used pesticides which may be present together with fluxapyroxad in real food samples (azoxystrobin, picoxystrobin, pyraclostrobin, kresoxim-methyl, fenhexamid, fluopicolide, pyrimethanil, and cyprodinil). Only a slight binding was observed with boscalid. Interestingly, the cross-reactivity was 10 times lower with antibodies obtained from hapten FXn than with FXc-type antibodies, indicating the relevance of the linker tethering site for antibody specificity.

Antibody affinity was evaluated by checkerboard cELISA using homologous (same hapten as that of the immunizing conjugate) and heterologous (the hapten was different from the immunizing conjugate) conjugates in two different assay procedures: the antibody-coated direct format and the conjugate-coated indirect format (Table 1). According to homologous assays, little difference was observed 
400 between the titers (antibody dilution affording an $A_{\max }$ value around 1.0 in the absence 401 of analyte in solution) of FXn- and FXc-type antibodies, and high-affinity antibodies to 402 fluxapyroxad were obtained from both of the immunizing haptens, with $\mathrm{IC}_{50}$ values 403 generally in the low nanomolar range. The only exception was antibody FXc\#1 which showed a high $\mathrm{IC}_{50}$ value in the indirect homologous assay. Therefore, the pyrazole ring seems to be a suitable linker tethering site in the fluxapyroxad molecule for highaffinity antibody generation. The lowest $I C_{50}$ value using homologous conjugates was obtained with antibody FXn\#2 in both assay formats. This result, together with the higher specificity of FXn-type antibodies, indicated a slight superiority of hapten FXn to elicit the best immune response. This finding could be explained by the minor changes introduced by the spacer arm in hapten FXn compared to the non-negligible changes in the electronic and conformational properties of the pyrazole ring produced by the 412 linker in hapten FXc as discussed above.

It is well established that heterologous conjugates can help to improve immunoassay sensitivity. However, if too drastic heterologies are used, binding of the antibody to the assay conjugate could be insufficient, particularly in the antibody416 coated format. The two haptens ( $F X n$ and $F X c)$ prepared in this study held the spacer 417 arm in proximal positions, so a similar orientation of the distal moieties was expected. 418 As envisioned, all of the antibodies recognized the corresponding heterologous 419 conjugate, including the enzyme tracer in the direct assay format, with the same or 420 similar titers (Table 1). The slope of the fitted inhibition curve was generally between 4210.8 and 1.0, and the background signal was always below 0.1. Mostly, assay sensitivity 422 could be enhanced by using the heterologous conjugates; the $\mathrm{IC}_{50}$ values were 423 generally reduced around $50 \%$ or more if compared to the homologous assay. The 
424 differences in the electronic and structural properties between both haptens did not 425 seem to hinder antibody binding. These results are in accordance with the 426 Landsteiner's principle ${ }^{25}$ stating that the specificity of antibodies is mainly directed 427 towards the distal moieties of small organic molecules.

428 The most sensitive immunoassays were found with antibody FXn\#2 in combination 429 with the heterologous conjugate, both in the direct and indirect assay formats. The 430 main analytical parameters of the standard curve of the best immunoassay in each 431 format are listed in Figure 5. Both standard curves showed $A_{\max }$ values over 1.0 and 432 slope values close to 1.0, which constitute excellent parameters for immunoassay 433 application. The $\mathrm{IC}_{50}$ for fluxapyroxad of the direct and indirect assays were $0.40 \mathrm{nM}$ $434(0.15 \mu \mathrm{g} / \mathrm{L})$ and $1.51 \mathrm{nM}(0.58 \mu \mathrm{g} / \mathrm{L})$, respectively. The calculated LOD values were 0.05 $435 \mathrm{nM}(0.019 \mu \mathrm{g} / \mathrm{L})$ and $0.12 \mathrm{nM}(0.046 \mu \mathrm{g} / \mathrm{L})$ for the direct and indirect assay, 436 respectively. Therefore, in this particular case, the sensitivity of the direct assay was 437 slightly better than that of the indirect assay, probably due to the antibody 438 characteristics. Generally, when polyclonal antibodies are used, heterologous 439 conjugates enhance assay sensitivity of both cELISA formats, and similar sensitivities 440 are usually attained with either format, as previously reported for other small chemical 441 compounds. ${ }^{26-28}$ Finally, the theoretical dynamic working range was established 442 between $0.09 \mathrm{nM}(0.034 \mu \mathrm{g} / \mathrm{L})$ and $4.30 \mathrm{nM}(1.640 \mu \mathrm{g} / \mathrm{L})$ for the direct assay, and 443 between $0.30 \mathrm{nM}(0.114 \mu \mathrm{g} / \mathrm{L})$ and $17.89 \mathrm{nM}(6.820 \mu \mathrm{g} / \mathrm{L})$ for the indirect format. Due 444 to their similar sensitivities, the two optimized immunoassays were further evaluated 445 for food sample analysis. 
446 Sample Analysis. Matrix effects of peach, apple, and grape juices were determined

447 by running standard curves of fluxapyroxad in juices diluted in water (from $1 / 5$ to 448 1/500). Very low interferences were seen with peach and apple juices in the direct 449 assay, whereas grape juice seemed to induce slight matrix effects (Figure S1). On the 450 other hand, similar results were found with the indirect assay, where the grape juice 451 showed the strongest interference (Figure S2). In all cases, a $1 / 25$ - or a $1 / 50$-fold 452 dilution seemed to minimize the observed matrix effects.

453 Next, peach, apple, and grape juices were fortified with fluxapyroxad and analyzed 454 by the developed immunoassays. Table 2 lists the recovery rates and the coefficients 455 of variation found by the direct and indirect cELISA. For the former assay, precise and 456 with just a $1 / 25$-fold sample dilution in water. Coefficients of variation higher than $20 \%$ were only seen for the lowest and the highest assayed concentration in apple and grape juice, respectively. For all three types of samples, the limit of quantitation (LOQ) of the direct immunoassay could be set at $5 \mu \mathrm{g} / \mathrm{L}$. Regarding the indirect assay, a $1 / 50$ fold sample dilution in water was required in order to obtain accurate and precise results (Table 2). Somewhat unprecise results were found with apple juice samples at the lowest assayed concentrations. On the contrary, good recovery rates and acceptable coefficients of variation were found for peach and grape juices spiked with fluxapyroxad at concentrations between 30 and $3000 \mu \mathrm{g} / \mathrm{L}$. Therefore, the LOQ of the indirect immunoassay could be established at $300 \mu \mathrm{g} / \mathrm{L}$ for apple juice and at $30 \mu \mathrm{g} / \mathrm{L}$

467 for peach and grape juices. Consequently, the LOQs displayed by the developed direct and the indirect cELISAs were much lower than the maximum residue limits (MRL) established for peach, apple, and grape samples by the European Commission (1500, 
470900 , and $3000 \mu \mathrm{g} / \mathrm{L}$, respectively) ${ }^{29}$ and by the US Department of Agriculture (3000,

471800 , and $2000 \mu \mathrm{g} / \mathrm{L}$, respectively). ${ }^{30}$ Nevertheless, in terms of sensitivity and

472 robustness, the direct assay seemed to be the best choice for the immunoanalysis of

473 fluxapyroxad residues in foodstuffs.

474 Due to the lack of juice samples with incurred residues and in order to provide 475 compelling evidences of the suitability of the direct cELISA for the determination of 476 fluxapyroxad residues under real conditions, a limited number of grapevines were 477 treated with a commercial formulation of the fungicide during the 2015/2016 season 478 near the harvest period. Grape samples were harvested three days after the treatment 479 with fluxapyroxad and extracted using the QuEChERS method. Extracts were directly analyzed by UPLC-MS/MS and by cELISA after 500-fold dilution in MilliQ water. Linear 481 regression analysis indicated an acceptable correlation between the developed direct 482 immunoassay and the reference chromatographic method $(y=1.09 x+15.12$;

$483 \quad r^{2}=0.963$ ), with only a slight deviation between both sets of measurements (Figure 6).

In summary, two haptens mimicking the molecule of fluxapyroxad were prepared 485 with the linker arm located at the same ring. Moreover, bioconjugates to different proteins were obtained with adequate yields by the active ester method using the 487 purified activated hapten, and antibodies to fluxapyroxad were generated for the first time. A slightly higher specificity was observed for those binders that were obtained from the hapten with the spacer arm at the N-1 position of the pyrazole ring. Highaffinity to fluxapyroxad was observed by $\mathrm{CELISA}$, with $\mathrm{IC}_{50}$ values in the low nanomolar range. Two immunoassays were developed in different formats with antibody FXn\#2 492 and using a heterologous conjugate. In the analysis of fruit juices, the direct assay 
493 outperformed the indirect assay in terms of sensitivity and robustness, so it was

494 applied to the quantitation of grape samples with incurred residues of fluxapyroxad,

495 with satisfactory results.

496 ASSOCIATED CONTENT

497 Supporting Information

498 General experimental procedures and techniques, preparation of 3',4',5'-trifluoro-

499 [1,1'-biphenyl]-2-amine (4), characterization data of intermediates of the synthesis of 500 hapten FXn, characterization data of intermediates of the synthesis of hapten FXc, 501 hapten activation and characterization of active esters, preparation of bioconjugates, 502 MALDI mass spectrometry analysis of immunizing and assay bioconjugates, 503 competitive ELISA procedures, antibody specificity (Table S1), juice matrix effects over 504 the direct immunoassay (Figure S1), juice matrix effects over the indirect immunoassay 505 (Figure S2), ${ }^{1} \mathrm{H}-\mathrm{NMR}$ spectra of haptens. This material is available free of charge via de 506 Internet at http://pubs.acs.org.

507 AUTHOR INFORMATION

508 Corresponding Author

509 Tel: +34-963900022; Fax: +34-963636301; E-mail: aabad@iata.csic.es

\section{ORCID iD}

511 Josep V. Mercader: 0000-0002-1838-2647

512 Antonio Abad-Somovilla: 0000-0002-5599-3682

513 Consuelo Agulló: 0000-0001-6056-5087

514 Antonio Abad-Fuentes: 0000-0001-5672-1438 


\section{$515 \quad$ Funding}

516 This work was supported by the Spanish Ministerio de Ciencia e Innovación (AGL2012-

517 39965-C02 and AGL2015-64488-C2) and cofinanced by European Regional

518 Development Funds.

519

520

\section{ACKNOWLEDGEMENTS}

522 Conjugate analysis was carried out at the Proteomics Unit - a member of ISCIII

523 ProteoRedProteomics Platform - and animal manipulation was carried out at the 524 Animal Production Section, both belonging to the SCSIE of the University of Valencia.

525 The collaboration of Javier Fernández Abellán in providing grapevine plots for fungicide 526 treatments is greatly appreciated. Limited amounts of the described immunoreagents 527 are available upon request for evaluation. http://www.haptens528 antibodies.com/en/descripcion-de-la-tecnologia/. 
531 (1) Avenot, H. F.; Michailides, T. J. Progress in understanding molecular mechanisms and evolution of resistance to succinate dehydrogenase inhibiting (SDHI) fungicides in phytopathogenic fungi. Crop Prot. 2010, 29, 643-651.

(2) Leroux, P.; Gredt, M.; Leroch, M.; Walker, A.-S. Exploring mechanisms of resistance to respiratory inhibitors in field strains of Botrytis cinerea, the causal agent of gray mold. Appl. Environ. Microbiol. 2010, 76, 6615-6630.

(3) Hu, M.-J.; Luo, C.-X.; Grabke, A.; Schnabel, G. Selection of a suitable medium to determine sensitivity of Monilinia fructicola mycelium to SDHI fungicides. J. Phytopathol. 2011, 159, 616-620.

(4) Fraaije, B. A.; Bayon, C.; Atkins, S.; Cools, H. J.; Lucas, J. A.; Fraaije, M. W. Risk assessment studies on succinate dehydrogenase inhibitors, the new weapons in the battle to control Septoria leaf blotch in wheat. Mol. Plant Pathol. 2012, 13, 263-275.

(5) AgroNews. http://news.agropages.com/News/NewsDetail---16362.htm; accessed September 14, 2017.

(6) Ye, Y.-H.; Ma, L.; Dai, Z.-C.; Xiao, Y.; Zhang, Y.-Y.; Li, D.-D.; Wang, J.-X.; Zhu, H.-L. Synthesis and antifungal activity of nicotinamide derivatives as succinate dehydrogenase inhibitors. J. Agric. Food Chem. 2014, 62, 4063-4071.

(7) Conclusion on the peer review of the pesticide risk assessment of the active substance fluxapyroxad (BAS 700 F). EFSA J. 2012, 10, 2522.

(8) Fluxapyroxad. EPA Pesticide Fact Sheet 2012. 
552 (9) Pesticide residues in food 2012. Joint FAO/WHO Meeting on Pesticide Residues. FAO Plant Production and Protection Paper 215, 2013.

554

555

556

557

558

559

560

561

562

563

564

565

566

567

568

569

570

571

572

573

(10) Raina, R. Chemical analysis of pesticides using GC/MS, GC/MS/MS, and LC/MS/MS. In Pesticides - Strategies for Pesticides Analysis; Stoytcheva, M. Ed.; InTech: Rijeka, Croatia, 2011, pp. 105-130.

(11) Dankwart, A. Immunochemical assays in pesticide analysis. In Encyclopedia of Analytical Chemistry, Meyers, R. A. Ed.; John Wiley \& Sons Ltd: Chichester, UK, 2006, pp. 1-27.

(12) Van Emon, J. M.; Chuang, J. C.; Dill, K.; Xiong, G. Immunoassays and biosensors. In Analysis of Pesticides in Food and Environmental Samples. Tadeo, J. L. Ed.; CRC Press, Taylor \& Francis Group: Boca Raton, FL, 2008, pp. 95-123.

(13) Ahn, K. C.; Kim, H.-J.; McCoy, M. R.; Gee, S. J.; Hammock, B. D. Immunoassays and biosensors for monitoring environmental and human exposure to pyrethroid insecticides. J. Agric. Food Chem. 2011, 59, 2792-2802.

(14) Xu, Z.-L.; Shen, Y.-D.; Zheng, W.-X.; Beier, R. C.; Xie, G.-M.; Dong, J.-X.; Yang, J.-Y.; Wang, H.; Lei, H.-T.; She, Z.-G.; Sun, Y.-M. Broad-specificity immunoassay for O,O-diethyl organophosphorous pesticides: application of molecular modeling to improve assay sensitivity and study antibody recognition. Anal. Chem. 2010, 82, 9314-9321.

(15) Marco, M.-P.; Gee, S.; Hammock, B. D. Immunochemical techniques for environmental analysis II. Antibody production and immunoassay development. Trends Anal. Chem. 1995, 14, 415-425. 
574 (16) López-Moreno, R.; Mercader, J. V.; Agulló, C.; Abad-Somovilla, A.; Abad-Fuentes,

575

576

577

578

579

580

581

582

583

584

585

586

587

588

589

590

591

592

593

594

595

596

A. Structure-immunogenicity relationship of kresoxim-methyl regioisomeric haptens. Org. Biomol. Chem. 2013, 11, 7361-7371.

(17) Parra, J.; Mercader, J. V.; Agulló, C.; Abad-Fuentes, A.; Abad-Somovilla, A. Concise and modular synthesis of regioisomeric haptens for the production of highaffinity and stereoselective antibodies to the strobilurin azoxystrobin. Tetrahedron 2011, 67, 624-635.

(18) Zhang, H.; Wang, S.; Fang, G. Applications and recent developments of multianalyte simultaneous analysis by enzyme-linked immunosorbent assays. J. Immunol. Methods 2011, 368, 1-23.

(19) Mercader, J. V.; Suárez-Pantaleón, C.; Agulló, C.; Abad-Somovilla, A.; AbadFuentes, A. Hapten synthesis and monoclonal antibody-based immunoassay development for the detection of the fungicide kresoxim-methyl. J. Agric. Food Chem. 2008, 56, 1545-1552.

(20) Suárez-Pantaleón, C.; Mercader, J. V.; Agulló, C.; Abad-Somovilla, A.; AbadFuentes, A. Forchlorfenuron-mimicking haptens: from immunogen design to antibody characterization by hierarchical clustering analysis. Org. Biomol. Chem. 2011, 9, 4863-4872.

(21) Mercader, J. V.; Agulló, C.; Abad-Somovilla, A.; Abad-Fuentes, A. Synthesis of siteheterologous haptens for high-affinity anti-pyraclostrobin antibody generation. Org. Biomol. Chem. 2011, 9, 1443-1453.

(22) Esteve-Turrillas, F. A.; Mercader, J. V.; Parra, J.; Agulló, C.; Abad-Somovilla, A.; Abad-Fuentes, A. Ready access to proquinazid haptens via cross-coupling 
597 chemistry for antibody generation and immunoassay development. PLoS One $598 \quad 2015,10, \mathrm{e} 0134042$.

599 (23) Abad-Fuentes, A.; Esteve-Turrillas, F. A.; Agulló, C.; Abad-Somovilla, A.; 600 Mercader, J. V. Development of competitive enzyme-linked immunosorbent 601 assays for boscalid determination in fruit juices. Food Chem. 2012, 135, 276-284.

602 (24) Lehotay, S. J. Determination of pesticide residues in foods by acetonitrile 603 extraction and partitioning with magnesium sulfate: collaborative study. J. AOAC

604 Int. 2007, 90, 485-520.

605

606 Publications: New York, 1962.

(26) Pastor-Navarro, N.; García-Bover, C.; Maquieira, A.; Puchades, R. Specific 608 polyclonal-based immunoassays for sulfathiazole. Anal. Bioanal. Chem. 2004, 609 $379,1088-1099$.

(27) Furzer, G. S.; Veldhuis, L.; Hall, J. C. Development and comparison of three diagnostic immunoassay formats for the detection of azoxystrobin. J. Agric. Food Chem. 2006, 54, 688-693.

(28) Esteve-Turrillas, F. A.; Mercader, J. V.; Agulló, C.; Marzo, J.; Abad-Somovilla, A.; Abad-Fuentes, A. Design and development of heterologous competitive immunoassays for the determination of boscalid residues. Analyst 2014, 139, 3636-3644. 
617 (29) EU - Pesticides Database. http://ec.europa.eu/food/plant/pesticides/eu-

618 pesticides-database/public/?event= homepage\&language=EN; accessed

$619 \quad$ September 14, 2017.

620 (30) Bryant Christie Inc. https://www.globalmrl.com/; accessed September 14, 2017.

621 
$622 \quad$ Figure legends

623 Figure 1. Molecular structure of fluxapyroxad.

624 Figure 2. Schematic representation of the synthesis and activation of hapten FXn.

625 Figure 3. Schematic representation of the synthesis and activation of hapten FXc.

626 Figure 4. MALDI-TOF-MS spectra of proteins (blue) and the corresponding

627 conjugates with haptens FXn (green) and FXc (orange): (A) BSA conjugates; (B) OVA

628 conjugates; (C) HRP conjugates.

629 Figure 5. Standard curve parameters of the best immunoassays in two different 630 formats $(n=3)$.

631 Figure 6. Comparison of results obtained by the developed direct CELISA and UPLC$632 \mathrm{MS} / \mathrm{MS}$ for fluxapyroxad analysis in grapes from in-field treated vineyards. Data are 633 from four independent determinations. 
Table 1. Checkerboard Screening Assay of Fluxapyroxad Antibodies $(n=3)$

\begin{tabular}{|c|c|c|c|c|c|c|c|c|c|c|c|c|}
\hline \multirow[b]{2}{*}{ antibody } & \multicolumn{6}{|c|}{ direct format } & \multicolumn{6}{|c|}{ indirect format } \\
\hline & $\begin{array}{c}\text { antibody } \\
\text { titer }\end{array}$ & $\begin{array}{l}\text { HRP } \\
\text { tracer }\end{array}$ & $\begin{array}{c}{[\mathrm{T}]^{\mathrm{a}}} \\
(\mathrm{ng} / \mathrm{mL})\end{array}$ & $A_{\max }$ & slope & $\begin{array}{l}\mathrm{IC}_{50} \\
(\mathrm{nM})\end{array}$ & $\begin{array}{l}\text { antibody } \\
\text { titer }\end{array}$ & $\begin{array}{c}\text { OVA } \\
\text { coating }\end{array}$ & $\begin{array}{c}{[\mathrm{C}]^{\mathrm{b}}} \\
(\mathrm{ng} / \mathrm{mL})\end{array}$ & $A_{\max }$ & slope & $\begin{array}{l}\mathrm{IC}_{50} \\
(\mathrm{nM})\end{array}$ \\
\hline \multirow[t]{2}{*}{ FXn\#1 } & $10^{4}$ & $\mathrm{FXn}$ & 30 & 2.19 & 1.00 & 10.6 & $10^{5}$ & FXn & 100 & 1.81 & 0.74 & 6.8 \\
\hline & $10^{4}$ & FXc & 30 & 1.13 & 0.67 & 2.2 & $10^{5}$ & FXc & 100 & 1.34 & 0.84 & 18.5 \\
\hline \multirow[t]{2}{*}{ FXn\#2 } & $3 \times 10^{4}$ & FXn & 30 & 1.93 & 0.81 & 0.9 & $10^{5}$ & FXn & 100 & 1.13 & 0.81 & 4.0 \\
\hline & $3 \times 10^{4}$ & FXc & 30 & 1.14 & 0.93 & 0.4 & $3 \times 10^{4}$ & FXc & 100 & 1.38 & 0.89 & 1.5 \\
\hline \multirow[t]{2}{*}{ FXc\#1 } & $10^{4}$ & FXn & 100 & 0.85 & 0.80 & 4.9 & $10^{4}$ & FXn & 100 & 1.28 & 0.81 & 8.8 \\
\hline & $10^{4}$ & FXc & 100 & 1.43 & 0.75 & 5.6 & $10^{5}$ & FXc & 100 & 1.30 & 0.60 & 141.6 \\
\hline \multirow[t]{2}{*}{$\mathrm{FX} c \# 2$} & $10^{4}$ & FXn & 30 & 1.39 & 0.89 & 1.1 & $3 \times 10^{4}$ & FXn & 100 & 1.13 & 0.65 & 2.6 \\
\hline & $3 \times 10^{4}$ & FXc & 30 & 1.35 & 0.62 & 1.9 & $10^{5}$ & $F X_{C}$ & 100 & 0.88 & 0.62 & 11.7 \\
\hline
\end{tabular}

${ }^{\mathrm{a}}$ Tracer concentration. ${ }^{\mathrm{b}}$ Coating conjugate concentration. 
Table 2. Recovery Values from Spiked Fruit Juices Using the Two Developed Immunoassays $(n=5)$.

\begin{tabular}{|c|c|c|c|c|c|c|c|}
\hline \multirow[b]{2}{*}{ immunoassay } & \multirow[b]{2}{*}{$\begin{array}{c}{[\mathrm{FXX}]^{\mathrm{a}}} \\
(\mu \mathrm{g} / \mathrm{L})\end{array}$} & \multicolumn{2}{|c|}{ peach } & \multicolumn{2}{|c|}{ apple } & \multicolumn{2}{|c|}{ grape } \\
\hline & & $\begin{array}{c}\text { recovered } \\
(\%)\end{array}$ & $\begin{array}{l}C V \\
(\%)\end{array}$ & $\begin{array}{c}\text { recovered } \\
(\%)\end{array}$ & $\begin{array}{l}\mathrm{CV} \\
(\%)\end{array}$ & $\begin{array}{c}\text { recovered } \\
(\%)\end{array}$ & $\begin{array}{l}\text { CV } \\
(\%)\end{array}$ \\
\hline \multirow[t]{7}{*}{ direct $^{\mathrm{b}}$} & 5 & 118.3 & 18.2 & 89.2 & 31.5 & 110.9 & 12.2 \\
\hline & 10 & 111.0 & 19.9 & 90.7 & 16.8 & 98.9 & 20.8 \\
\hline & 20 & 102.8 & 12.1 & 95.5 & 12.7 & 97.4 & 16.0 \\
\hline & 50 & 97.4 & 6.5 & 90.5 & 4.5 & 87.3 & 17.4 \\
\hline & 100 & 92.1 & 11.0 & 85.2 & 9.9 & 86.8 & 11.9 \\
\hline & 200 & 86.9 & 16.0 & 81.5 & 4.8 & 80.5 & 2.9 \\
\hline & 500 & 90.7 & 10.7 & 92.5 & 11.8 & 107.8 & 30.5 \\
\hline \multirow[t]{6}{*}{ indirect $^{c}$} & 30 & 127.7 & 18.9 & 101.4 & 43.3 & 114.2 & 28.7 \\
\hline & 100 & 116.0 & 19.2 & 101.2 & 34.0 & 114.0 & 19.3 \\
\hline & 300 & 112.3 & 7.7 & 112.4 & 11.7 & 98.4 & 15.4 \\
\hline & 500 & 100.3 & 4.0 & 102.0 & 6.3 & 91.8 & 16.9 \\
\hline & 1000 & 98.0 & 8.4 & 91.4 & 5.7 & 85.2 & 14.5 \\
\hline & 3000 & 93.7 & 6.3 & 95.4 & 15.3 & 78.6 & 22.7 \\
\hline
\end{tabular}

${ }^{a}$ Spiked fluxapyroxad concentration. ${ }^{b}$ Samples were 25 -fold diluted in MilliQ water. ${ }^{\mathrm{c}}$ Samples were 50 -fold diluted in MilliQ water. 


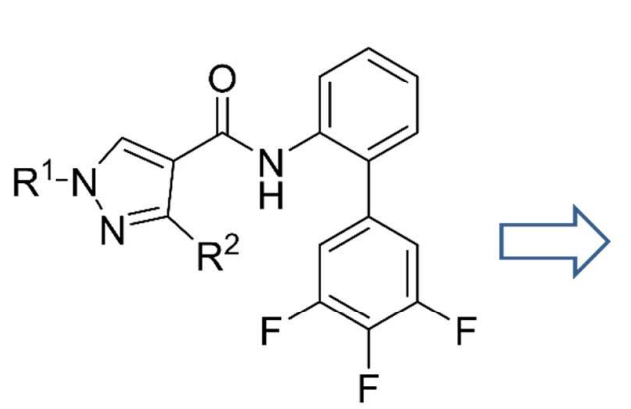

Fluxapyroxad

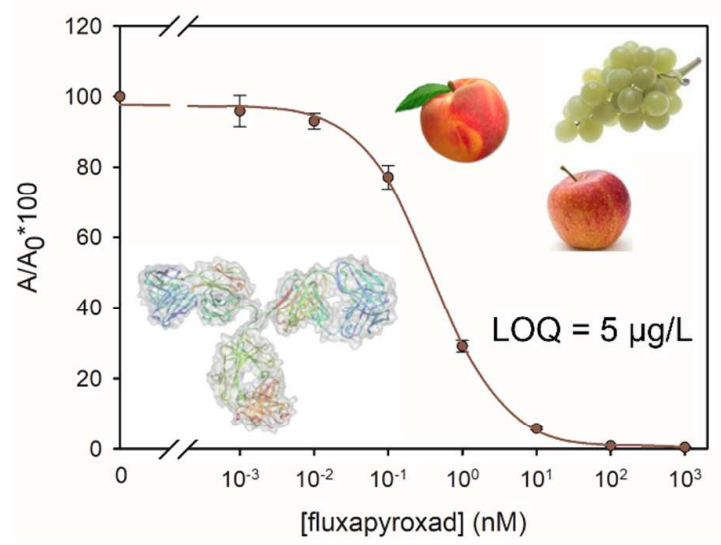




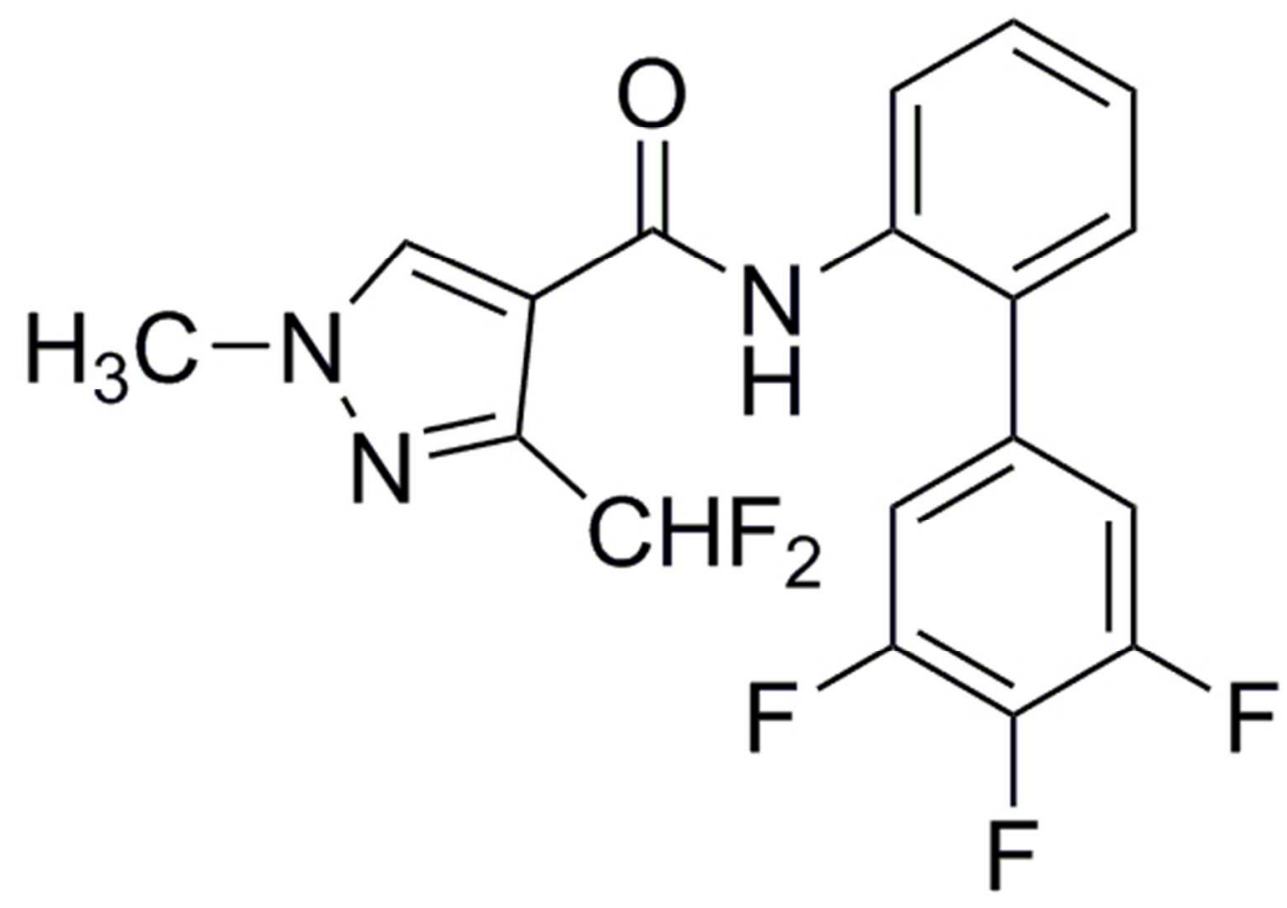

Figure 1. Molecular structure of fluxapyroxad.

$47 \times 33 \mathrm{~mm}(300 \times 300$ DPI $)$ 

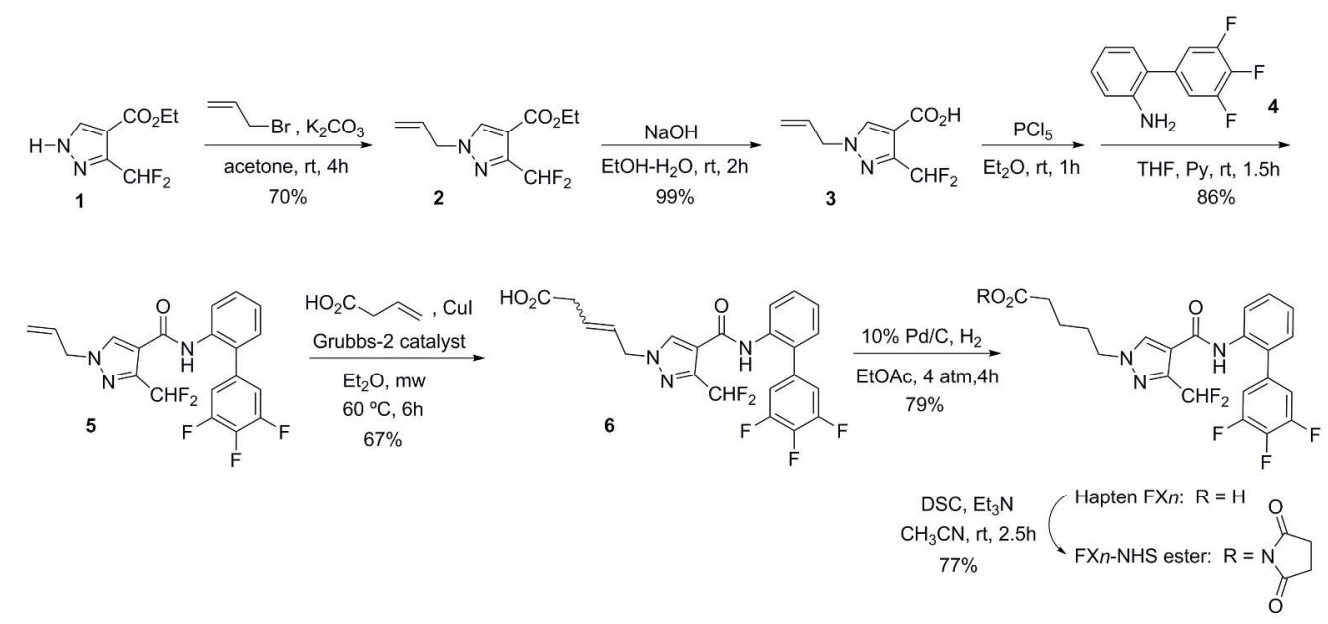

Figure 2. Schematic representation of the synthesis and activation of hapten FXn.

$235 \times 109 \mathrm{~mm}(300 \times 300$ DPI $)$ 

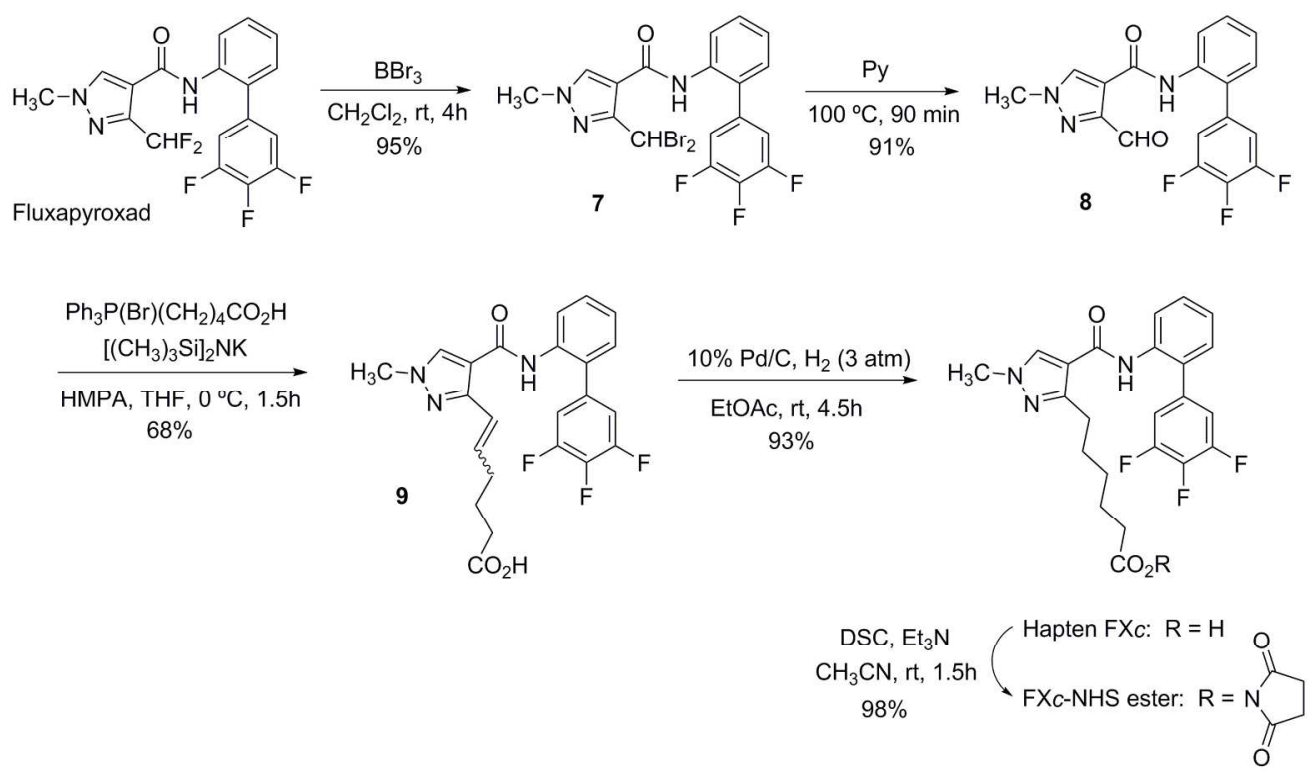

Figure 3. Schematic representation of the synthesis and activation of hapten FXc $198 \times 115 \mathrm{~mm}(300 \times 300$ DPI $)$ 

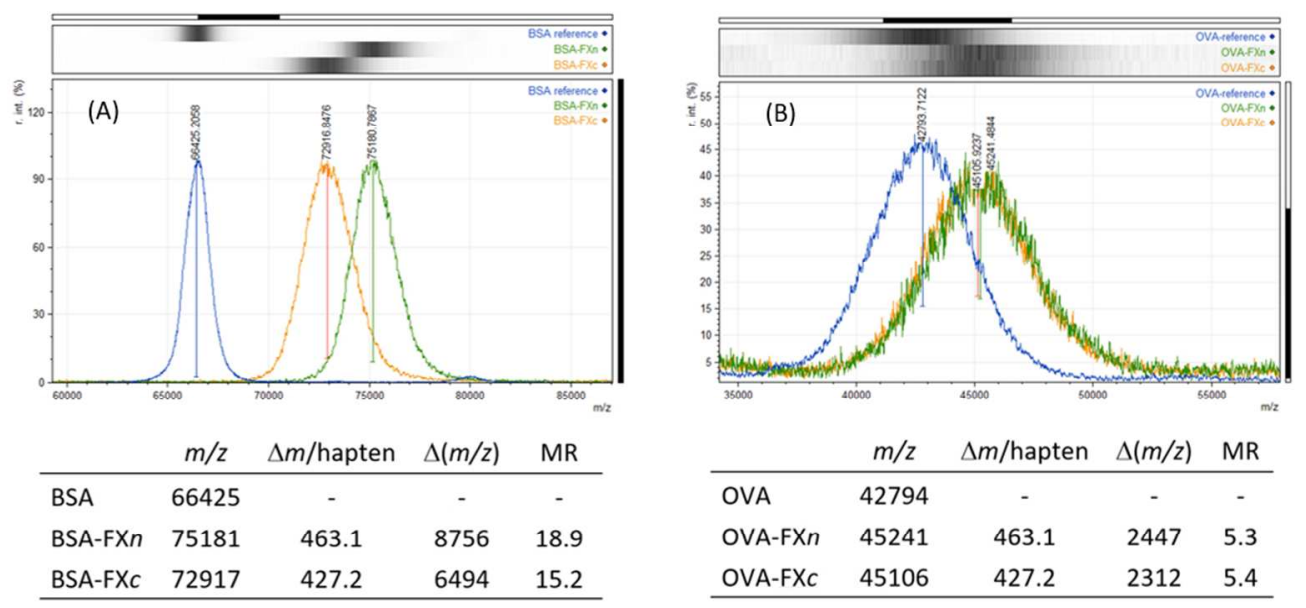

\begin{tabular}{lcccc} 
& $m / z$ & $\Delta m /$ hapten & $\Delta(m / z)$ & $\mathrm{MR}$ \\
\hline OVA & 42794 & - & - & - \\
OVA-FXn & 45241 & 463.1 & 2447 & 5.3 \\
OVA-FXc & 45106 & 427.2 & 2312 & 5.4 \\
\hline
\end{tabular}

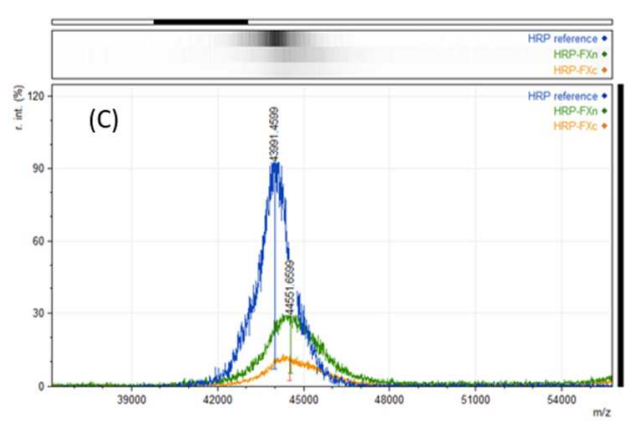

\begin{tabular}{lcccc} 
& $m / z$ & $\Delta m /$ hapten & $\Delta(m / z)$ & MR \\
\hline HRP & 43991 & - & - & - \\
HRP-FXn & 44552 & 463.1 & 561 & 1.2 \\
HRP-FXc & 44536 & 427.2 & $545 \times$ & 1.3 \\
\hline
\end{tabular}

Figure 4. MALDI-TOF-MS spectra of proteins (blue) and the corresponding conjugates with haptens FXn (green) and FXc (orange): (A) BSA conjugates; (B) OVA conjugates; (C) HRP conjugates.

$187 \times 156 \mathrm{~mm}(150 \times 150 \mathrm{DPI})$ 


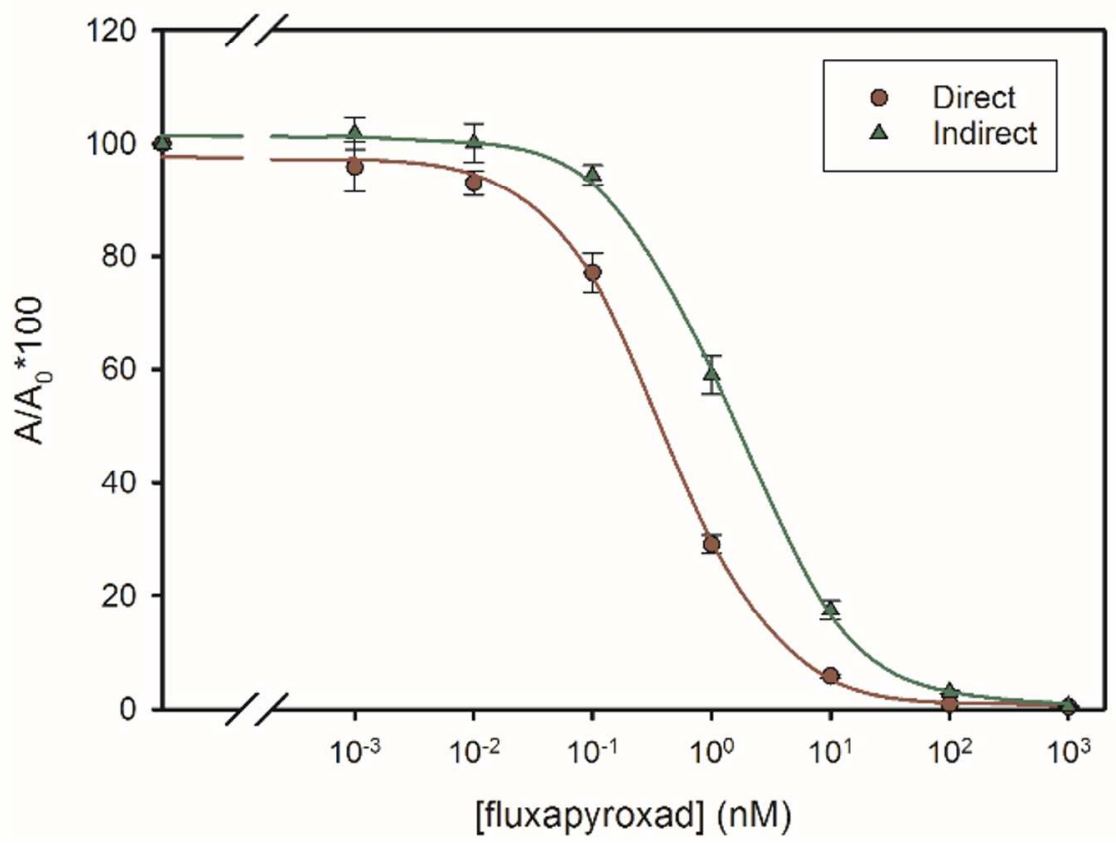

\begin{tabular}{lcc} 
& direct format & indirect format \\
\cline { 2 - 3 } antibody & $\mathrm{FXn \# 2}$ & $\mathrm{FXn \# 2}$ \\
(titer) & $\left(3 \times 10^{4}\right)$ & $\left(3 \times 10^{4}\right)$ \\
conjugate & $\mathrm{HRP}-\mathrm{FXC}$ & OVA-FXC \\
& $30 \mathrm{ng} / \mathrm{mL}$ & $100 \mathrm{ng} / \mathrm{mL}$ \\
& $1.14 \pm 0.16$ & $1.38 \pm 0.25$ \\
$\mathrm{Amax}_{\mathrm{max}}$ & $0.40 \pm 0.07$ & $1.51 \pm 0.21$ \\
$\mathrm{IC}_{50}(\mathrm{nM})$ & $0.93 \pm 0.11$ & $0.89 \pm 0.02$ \\
slope & $0.006 \pm 0.007$ & $0.009 \pm 0.003$ \\
Amin &
\end{tabular}

Figure 5. Standard curve parameters of the best immunoassays in two different formats $(n=3)$. $319 \times 420 \mathrm{~mm}(150 \times 150 \mathrm{DPI})$ 


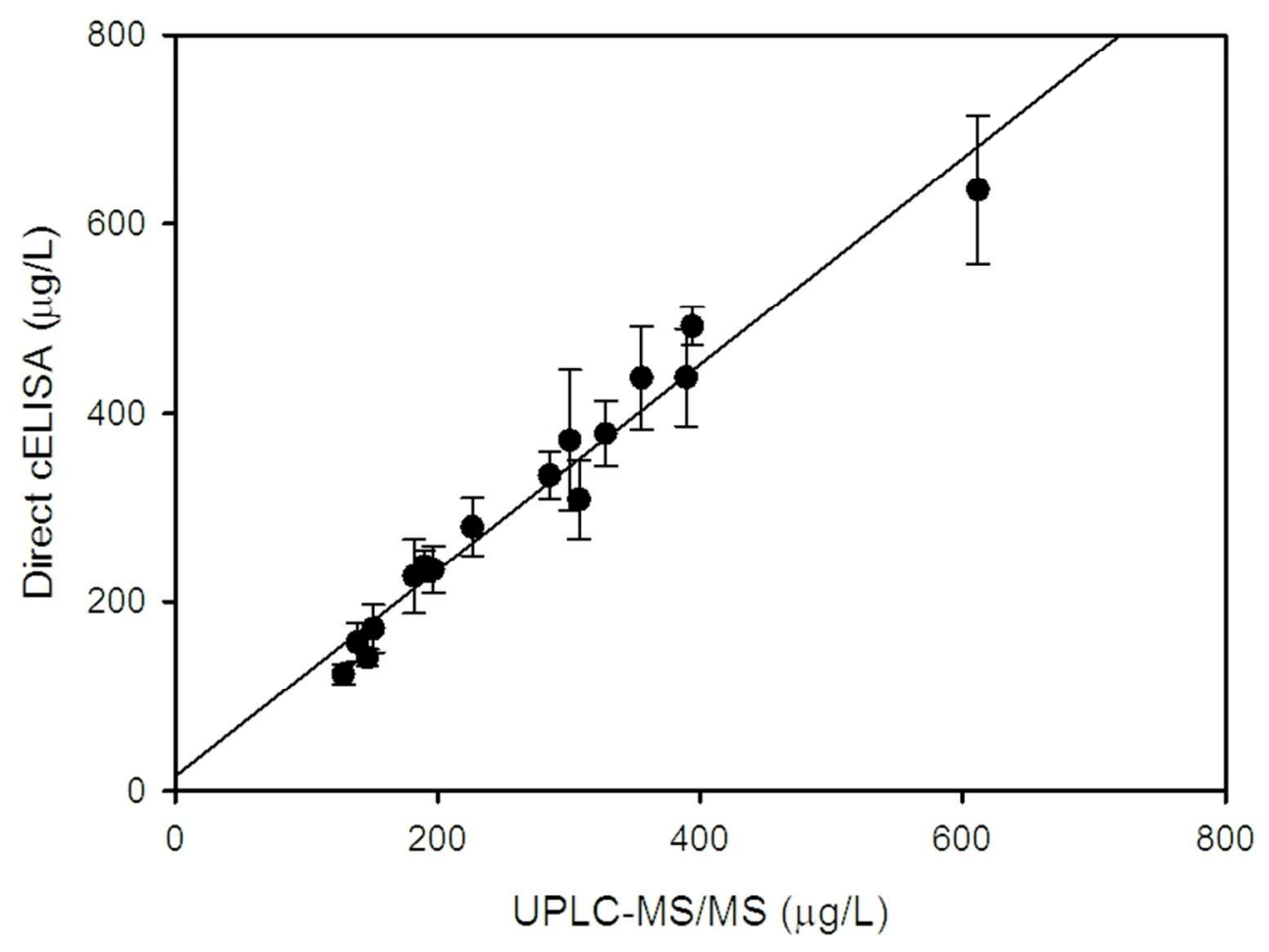

Figure 6. Comparison of results obtained by the developed direct cELISA and UPLC-MS/MS for fluxapyroxad analysis in grapes from in-field treated vineyards. Data are from four independent determinations.

$151 \times 120 \mathrm{~mm}(150 \times 150 \mathrm{DPI})$ 